\title{
Observations of Comet 1898 VII
}

with the Equatorials at the Royal Observatory Cape of Good Hope.

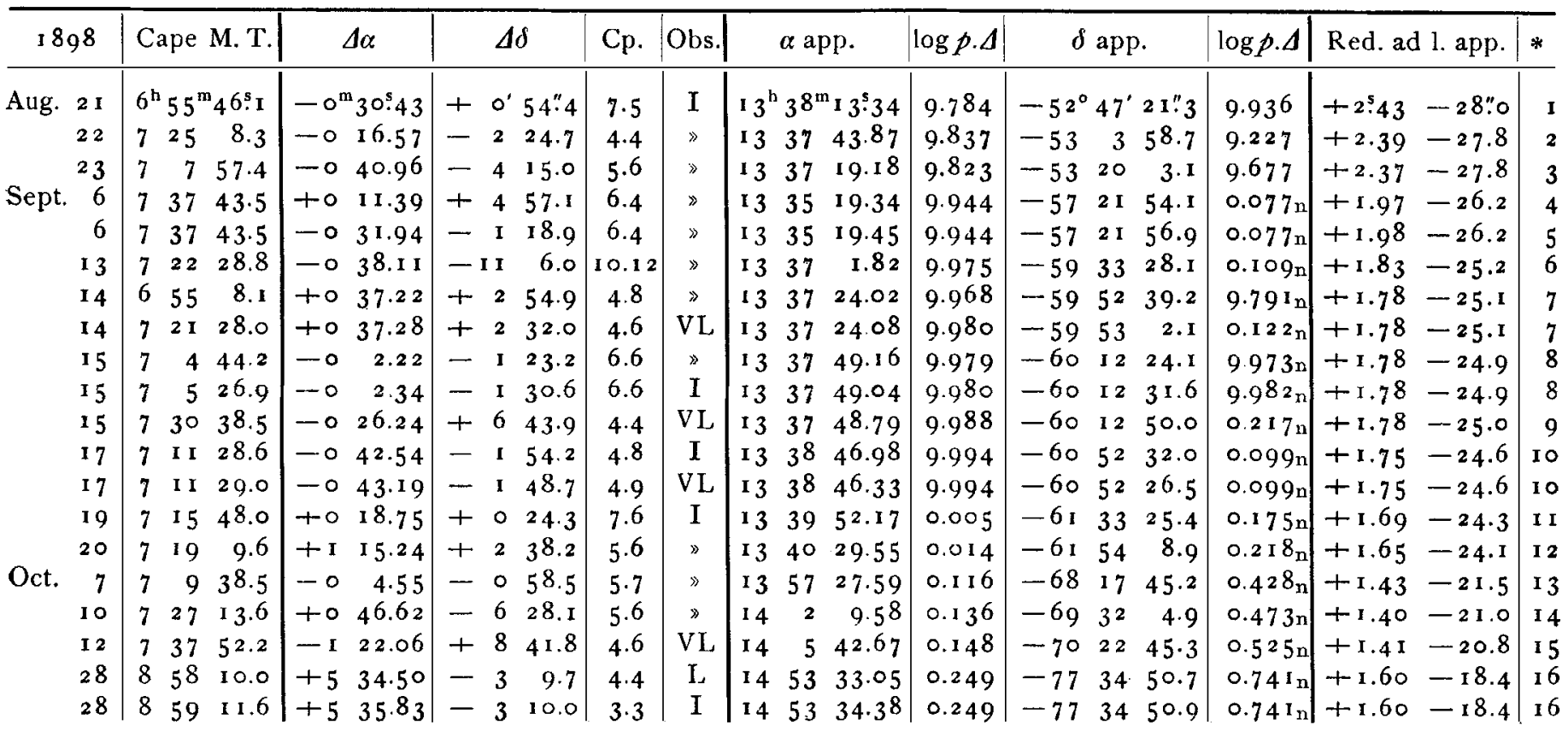

Made with the Repsold filar micrometer.

All the observations (except that of the $28^{\text {th }}$ October, which was made with the 18 in. visual telescope of the $\mathrm{Mc}$ Clean equatorial) were made with the 7 inch equatorial and are corrected for refraction.

Observers: $\mathrm{L}=$ Foseph Lunt; $\mathrm{I}=R . T$. A. Innes; VL $=$ Victor A. Löwinger.

Mean Places of the Comparison Stars.

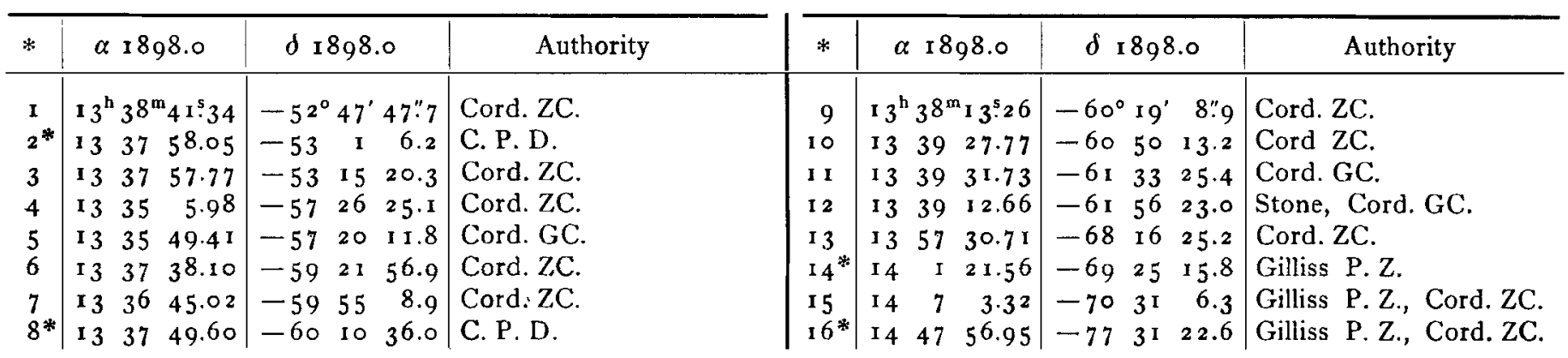

Notes. Aug. 21. Faint. - Aug. 23. Very bad definition. - Sept. 6. Faint, bad definition; no nucleus seen.

Royal Observatory, Cape of Good Hope, 1899 Febr. $10^{\text {th }}$.

David Gill, H. M. Astronomer.

* These stars will be reobserved on the meridian.

\section{Ueber den Begleiter von $\beta$ Orionis.}

Im Anschluss an die Notiz von R. G. Aitken in Publ. Astr. Soc. of the Pacific No. 66 p. 45 möchte ich bemerken, dass meine Frau und ich gleich nach Aufstellung unseres Siebenzöllers 1894 März I7, 19 und April 2 den RigelBegleiter deutlich länglich gesehen haben. Am letztgenannten

Lussinpiccolo, I 899 März I I.
Tage betrug der Positionswinkel der Verlängerung nach einer Schätzung im Ocular ca. $190^{\circ}$, nach einer Ausmessung einer aufgenommenen Zeichnung $183^{\circ}$, während der Positionswinkel des Begleiters gegen Rigel auf $200^{\circ}$ bis $210^{\circ}$ geschätzt wurde. 1895 und 1896 erschien der Begleiter rund.

\section{Brenner.}

